\title{
Review Article \\ Endogenous and Synthetic Cannabinoids as Therapeutics in Retinal Disease
}

\author{
Despina Kokona, ${ }^{1,2}$ Panagiota-Christina Georgiou, ${ }^{1}$ Mihalis Kounenidakis, ${ }^{1}$ \\ Foteini Kiagiadaki, ${ }^{1}$ and Kyriaki Thermos ${ }^{1}$ \\ ${ }^{1}$ University of Crete, School of Medicine, Department of Pharmacology, Heraklion, 71003 Crete, Greece \\ ${ }^{2}$ Department of Ophthalmology, Bern University Hospital, Inselspital, 3010 Bern, Switzerland
}

Correspondence should be addressed to Kyriaki Thermos; thermos@med.uoc.gr

Received 26 June 2015; Revised 16 November 2015; Accepted 1 December 2015

Academic Editor: Christian Casanova

Copyright (c) 2016 Despina Kokona et al. This is an open access article distributed under the Creative Commons Attribution License, which permits unrestricted use, distribution, and reproduction in any medium, provided the original work is properly cited.

The functional significance of cannabinoids in ocular physiology and disease has been reported some decades ago. In the early 1970s, subjects who smoked Cannabis sativa developed lower intraocular pressure (IOP). This led to the isolation of phytocannabinoids from this plant and the study of their therapeutic effects in glaucoma. The main treatment of this disease to date involves the administration of drugs mediating either the decrease of aqueous humour synthesis or the increase of its outflow and thus reduces IOP. However, the reduction of IOP is not sufficient to prevent visual field loss. Retinal diseases, such as glaucoma and diabetic retinopathy, have been defined as neurodegenerative diseases and characterized by ischemia-induced excitotoxicity and loss of retinal neurons. Therefore, new therapeutic strategies must be applied in order to target retinal cell death, reduction of visual acuity, and blindness. The aim of the present review is to address the neuroprotective and therapeutic potential of cannabinoids in retinal disease.

\section{Introduction}

The study of cannabinoids in the central nervous system (CNS) has been the primary focus of many investigations, not only due to their psychotropic effects, but also due to their involvement in neuroplasticity and their therapeutic use in conditions such as obesity, pain, and neurodegenerative diseases. Fewer studies have focused on the role of cannabinoids in the retina, as well as other critical players of the visual system $[1,2]$.

The functional significance of the cannabinoids in ocular physiology and disease was noted by Hepler and Frank [3] who reported that subjects who smoked marijuana (Cannabis sativa) developed lower intraocular pressure (IOP). This finding was subsequently reproduced and the results suggested that cannabinoids isolated from cannabis may be useful in the treatment of glaucoma [4-6].

The presence of a functional endocannabinoid system in the retina, which includes (a) endogenous cannabinoids, (b) enzymes involved in their synthesis and metabolism, and

(c) cannabinoid receptors, supports a role for cannabinoids in retinal circuitry and vision [1]. Arachidonoyl ethanolamide (anandamide, AEA) and 2-arachidonoylglycerol (2-AG) have been found in retinas of many species [7-10].

Two receptors have been cloned, $\mathrm{CB} 1$ and $\mathrm{CB} 2$, that mediate the physiological and pharmacological actions of endocannabinoids, as well as the actions of the natural and synthetic cannabinoids [11-15]. CB1 receptors are predominant in the CNS and are expressed in brain areas that influence motor and cognitive functions $[1,2]$, as well as in areas that comprise the visual pathway of the brain, namely, the thalamus and visual cortex [16-18]. CB2 receptors are also found in the CNS, but their location and function are mainly in peripheral tissues and the immune system $[19,20]$.

The aim of this review is to summarize the knowledge acquired to date on the function of endogenous and synthetic cannabinoids in the retina and to address the neuroprotective and therapeutic potential of cannabinoids in retinal disease. 


\section{Endocannabinoid System in Retina}

2.1. Cannabinoid Receptor Localization in Retinal Neurons. Immunohistochemical studies described the presence and localization of the CB1 receptor in retinal neurons of several animal species [10]. Specifically, CB1 immunoreactivity was detected in the inner and outer plexiform layers (and/or on cone pedicles and rod spherules) of tiger salamander, gold fish, chick, mouse, rat, and rhesus monkey, in amacrine and retinal ganglion cells (RGCs) and ganglion cell axons of all species except gold fish, and sparsely labeled photoreceptors of monkey, mouse, rat, and chicken. CB1 immunoreactivity has been detected in rod bipolar cells, GABA-amacrine cells, and horizontal cells [21]. In the mouse retina, a specific cannabinoid circuitry has been defined based on colocalization of the $\mathrm{CB} 1$ receptor and a repertoire of proteins that influence the endocannabinoid system [22].

The expression of CB2 cannabinoid receptor mRNA has been reported in adult rat retina, as well as in human retinal pigment epithelial cells (mRNA and protein) [23, 24]. Immunohistochemical studies supported the presence of CB2 receptors in retinal tissue of rats and mice $[25,26]$. Specifically, the CB2 receptor was localized in the retinal pigment epithelium, inner photoreceptor segments, horizontal and amacrine cells, ganglion cell layer (GCL), and inner plexiform layer (IPL) of the rat retina and in all five neuronal types of the mouse retina. The presence of CB2 receptors in Müller cells of monkeys has also been reported [27]. However, different groups, employing radioligand binding studies in rat retinal membranes, suggested the absence or low undetectable levels of CB2 receptor in rat retina $[28,29]$. Thus, further studies are needed in order to elucidate the presence and functional role of $\mathrm{CB} 2$ receptors in the rodent retina.

Two other receptor systems were shown to be activated by cannabinoids, namely, the transient receptor potential cation channel subfamily V member 1 (TRPV1 channel) and the orphan receptor GPR55 [30-34]. Immunohistochemical studies have shown the expression of TRPV1 channel in IPL, INL (inner nuclear layer), and GCL of adult rat retina, while GPR55 has been detected in rod photoreceptors of adult vervet monkey retina $[33,34]$. The colocalization of GPR55 only with the inner segments of rod photoreceptors, with less immunoreactivity observed in peripheral retina regions, suggested that this asymmetric distribution of GPR55 in the monkey retina may underlie its function in phototransduction [34].

Both $\mathrm{CB} 1$ and $\mathrm{CB} 2$ cannabinoid receptors belong to the GPCR family [11-14]. The most well-known signal transduction response for both $\mathrm{CB} 1$ and $\mathrm{CB} 2$ receptors is the inhibition of adenylyl cyclase through interaction with $\mathrm{Gi} /$ o proteins $[12$, 35]. Activation of $\mathrm{CB} 1$ receptors affects G-protein-coupled inwardly rectifying potassium channels (GIRKs) [36, 37]. CB1 receptors interact with a variety of ion channels including $\mathrm{Ca}^{2+}$ and $\mathrm{K}^{+}$channels [37-39].

2.2. Endocannabinoids in the Retina: Synthesis and Metabolism. AEA and 2-AG, as well as the enzymes responsible for their synthesis (N-acyl phosphatidylethanolamine phospholipase, D-NAPE-PLD, diacylglycerol lipase, DAGL) and degradation [fatty acid amide hydrolase (FAAH), monoacylglycerol lipase (MGL)], have been found in the retina of rodents and other mammals $[8,9,22]$. Immunohistochemical localization of DAGL has been reported in retinal tissue, especially in the postsynaptic terminals of cone bipolar cells. Yet despite the reported presence of NAPE-PLD in rat retina little is known about its specific localization in rat retinal neurons [40]. FAAH, the metabolic enzyme of AEA [41], has been shown to be localized in photoreceptor inner segments, horizontal, dopaminergic, and cholinergic amacrine and ganglion cells, as well as Müller cells, in the rodent retina $[21,22]$. MGL, the metabolic enzyme of 2-AG [42], has also been reported in retinal tissue and specifically in the IPL and OPL (outer plexiform layer) [22].

\subsection{Function of Cannabinoid CB1 Receptors in the Retina.} As mentioned above, CB1 receptors can interact with a variety of ion channels [37-39]. In the retina $\mathrm{CB1}$ receptor activation results in pertussis toxin sensitive actions (Gi/olinked CB1 receptor), such as the modulation of ion channel function [43]. This cannabinoid function may influence retinal circuitry, neurotransmitter release, and neuroprotection. In retina, cannabinoids have been reported to modulate $\mathrm{Ca}^{2+}$ and/or $\mathrm{K}^{+}$channels in bipolar cells and photoreceptors $[10,44-46]$. The presence of CB1 receptors in rod bipolar cells and the CB1-dependent reduction in the amplitude of voltage-gated L-type calcium channel currents present in these retinal neurons suggest that endocannabinoids and synthetic cannabinoids may play an important role in retinal circuitry and in scotopic vision [21].

Glutamate is the major neurotransmitter in the retina released from photoreceptors, rod bipolar and ganglion cells. However, a plethora of other neurotransmitters is found in amacrine and horizontal cells. The presence of the CB1 receptor in all retinal neurons suggests that endocannabinoids and synthetic cannabinoids play a neuromodulatory role in retinal circuitry by influencing the release of other neurotransmitters. CB1 receptor agonists inhibited $\mathrm{K}^{+}$ induced $\left[{ }^{3} \mathrm{H}\right]-\mathrm{D}$-aspartate release from bovine retina, and $\mathrm{Ca}^{2+}$ evoked $\left[{ }^{3} \mathrm{H}\right]$-noradrenaline and $\left[{ }^{3} \mathrm{H}\right]$-dopamine release in guinea pig retina [47-49]. CB1 regulation of GABA release was reported by spontaneous mini frequencies involving GABA-A receptor-mediated inward currents, in cultured chick embryonic amacrine cells [50]. The authors of this study concluded that the "regulation of spontaneous transmitter release by endocannabinoids might be important in network maintenance in amacrine cells and other inhibitory interneurons."

In rat retinal explants HU-210 attenuated the release of the inhibitory neuropeptide somatostatin in a dose-dependent bimodal manner via the activation of the CB1 receptor (Figure 1). Bimodal modulation was also reported in a study that showed that WIN55212-2 affected voltage-dependent currents of retinal cones in a biphasic manner [45].

The GPR55 receptor and the TRPV1 channel are also activated by cannabinoids, such as the endogenous cannabinoid AEA, the synthetic cannabinoid CP55940, and the nonpsychotropic cannabinoid CBD [30-34]. Recently, the presence of GPR55 receptor protein in rod photoreceptor 


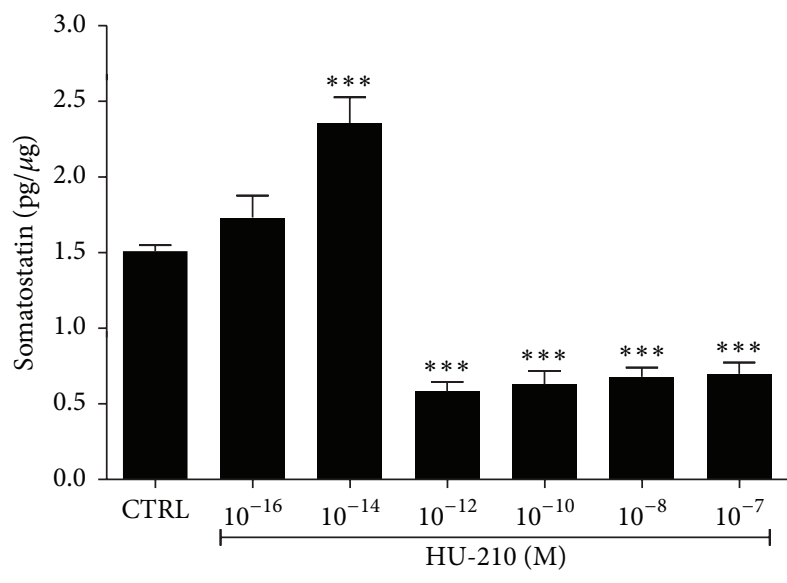

(a)

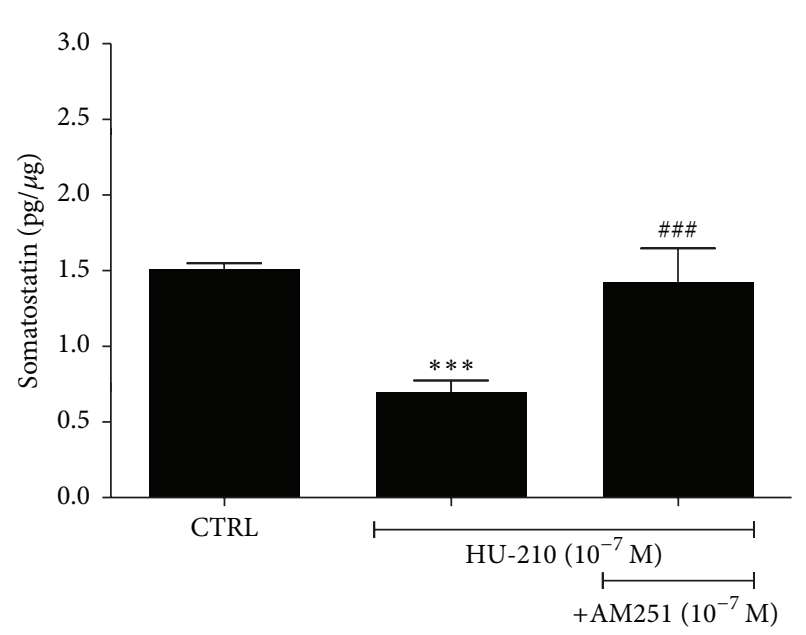

(b)

FIGURE 1: Effect of HU-210 on somatostatin's release in rat retina. (a) HU-210 at the low dose of $10^{-16} \mathrm{M}$ had no effect on the release of somatostatin $(1.7 \pm 0.15 \mathrm{pg} / \mu \mathrm{g}, n=4)$ compared to the control tissue (CTRL, $1.5 \pm 0.04 \mathrm{pg} / \mu \mathrm{g}, n=12)$. HU-210 at $10^{-14} \mathrm{M}$ increased the release of somatostatin in the retina $\left(2.4 \pm 0.17 \mathrm{pg} / \mu \mathrm{g}, n=5,{ }^{* * *} p<0.001\right.$ compared to CTRL), whereas higher concentrations caused a statistically significant decrease in somatostatin's release $\left(10^{-12} \mathrm{M}, 0.6 \pm 0.06 \mathrm{pg} / \mu \mathrm{g}, n=5,{ }^{* * *} p<0.001\right.$ compared to CTRL; $10^{-10} \mathrm{M}, 0.63 \pm 0.09 \mathrm{pg} / \mu \mathrm{g}$, $n=5,{ }^{* * *} p<0.001$ compared to CTRL; $10^{-8} \mathrm{M}, 0.68 \pm 0.06 \mathrm{pg} / \mu \mathrm{g}, n=6,{ }^{* * *} p<0.001$ compared to CTRL; $10^{-7} \mathrm{M}, 0.7 \pm 0.07 \mathrm{pg} / \mu \mathrm{g}, n=6$, ${ }^{* * *} p<0.001$ compared to CTRL). Dunnett's Multiple Comparison Test was used for the statistical analysis of the data. All values represent the mean \pm SEM. (b) Effect of the CB1 preferred antagonist AM251 in the actions of HU-210 $\left(10^{-7} \mathrm{M}\right)$ on somatostatin's release. AM251 $\left(10^{-7} \mathrm{M}\right)$ reversed the attenuation of somatostatin release by HU-210 $\left(10^{-7} \mathrm{M}\right)\left(1.42 \pm 0.22 \mathrm{pg} / \mu \mathrm{g},{ }^{\# \#} p<0.001\right.$ compared to HU-210, $\left.n=5\right)$. One-way ANOVA with Tukey's post hoc analysis test was used for the statistical analysis of the data. All values represent the mean \pm SEM.

cells of the vervet monkey was reported and the authors suggested that GPR55 activation in these cells may play a role in scotopic vision [34]. However, more studies are needed in order to evaluate the role of GPR55 receptor in retinal circuitry. The TRPV1 channel has been recently suggested to be involved in RGC function and survival in the retina [51]. Further studies regarding the neuroprotective actions of the TRPV1 channel in retina, upon its activation by the cannabinoids, are presented in Section 3.2.

\section{Cannabinoids as Therapeutics in Retinal Disease}

3.1. Ischemia-Induced Retinal Diseases. Glaucoma is the second cause of blindness worldwide and is characterized by elevation of IOP [52]. The main treatment of the disease to date involves the administration of drugs that reduce IOP by affecting either aqueous humour synthesis or outflow (cholinomimetics or cholinesterase inhibitors, alpha adrenergic receptor agonists, beta adrenergic receptor blockers, and others). The CB1 receptor was found to be localized in the anterior segment of the human and rat eye, including the ciliary body, epithelium, and the trabecular meshwork $[53,54]$. These ocular tissues regulate aqueous humour inflow and outflow pathways and IOP. McIntosh et al. [55] reported that endogenous CB1 receptors couple with both $\mathrm{Gq} / 11$ and $\mathrm{Gi} / \mathrm{o}$, present in the trabecular meshwork, and elicit different responses according to the cannabinoid agonist employed in the study. Activation of CB1 receptors by WIN55,2122, but not by CP55,940 or methanandamide, led to CB1 receptor coupling with $\mathrm{Gq} / 11$ and subsequent activation of
PLC-dependent increase of intracellular $\mathrm{Ca}^{2+}$ levels. This study suggested that the differential effects of cannabinoid agonists in human trabecular meshwork cells may be used to identify cannabinoids that affect aqueous outflow and IOP. These pharmacological actions of cannabinoids render them useful therapeutic targets in lowering IOP in glaucoma patients.

However, the reduction of IOP is not sufficient to prevent visual field loss. The pathophysiology of glaucoma is multifactorial and recently more and more studies define glaucoma as a neurodegenerative disease, characterized by ischemiainduced excitotoxicity and loss of RGCs [56-59]. Elevated glutamate levels have been detected in the vitreous of humans and monkeys with glaucoma [60] and glutamate-induced excitotoxicity has been suggested to play a fundamental role in the RGCs loss observed in experimental glaucoma [61].

Diabetic retinopathy is another major ocular disease. While being defined by its microvascular characteristics (neovascularization), more recent reports suggest that it possesses neurodegenerative and inflammatory components [62]. In fact, it has been suggested that retinal function is compromised before the appearance of neovascularization in diabetic patients [63-65]. Oxidative stress has also been documented in both animals and diabetic patients and has been correlated with neuronal loss [66-68].

Many strategies have been used to develop therapeutic agents for the successful treatment of ischemia-induced retinopathies and the prevention of blindness [69]. The proneovascular agent vascular endothelium growth factor (VEGF) is considered to be the factor most responsible for the development of new vessels in diseases, such as proliferative 
DR. The discovery of anti-VEGF therapy has given new hope to patients, yet this treatment targets only the neovascular component of ischemia-induced retinopathies and has serious ocular adverse effects [70-72]. However, there are no therapeutics available to date to treat the neurodegenerative component of diabetic retinopathy or glaucoma (for a review, see [73]). In order to preserve vision, all three components of ischemia-induced retinopathies, neovascularization, neurodegeneration, and inflammation, must be addressed.

\subsection{Cannabinoids as Neuroprotectants in Retinal Disease} Models. Different animal disease models have been employed to examine the neuroprotective effects of putative therapeutics to treat neurodegenerative retinal diseases. These include ex vivo and in vivo models of ischemia and excitotoxicity, such as the ex vivo chemical ischemia model, the ex vivo and in vivo NMDA (N-methyl-D-aspartate) or AMPA ( $\alpha$-amino-3-hydroxy-5-methyl-4-isoxazolepropionic acid) models of excitotoxicity, and the in vivo animal models of IOP-reperfusion (glaucoma), and the streptozotocin (STZ) model of diabetic retinopathy [73].

The ex vivo model of chemical ischemia involves the blockade of oxidative phosphorylation and glycolysis and is believed to be useful for the understanding of the early events underlying the pathophysiology of ischemia [74]. It was previously reported that chemical ischemia influences the viability of a variety of amacrine and rod bipolar cells, but not RGC or photoreceptor viability [75]. HU210 afforded neuroprotection to cholinergic amacrine and rod bipolar cells via activation of the CB1 receptor (Figures 2 and 3(a)). These results were also substantiated by TUNEL staining (Figure 3(b)).

The underlying cause of ischemia-induced cell death is excitotoxicity. Ischemic insults lead to activation of voltage gated calcium channels and increase in glutamate levels and activation of ionotropic glutamate (NMDA and AMPA) receptors leading to an excess of intracellular calcium ions [60]. NMDA has been the excitatory amino acid of choice as a model of ischemia-induced cell death in brain and retina. However, the AMPA excitotoxicity model has also been employed. $\Delta^{9}$-Tetrahydroxycannabinol ( $\Delta^{9}$-THC; partly via a CB1 mechanism) and the non-CB1 agonist CBD were shown to protect the retina from NMDA excitotoxicity [76]. Both cannabinoids afforded neuroprotection to retinal neurons located in the INL and GCL via attenuation of lipid peroxidation and/or nitrotyrosine formation [76]. Intravitreal administration of AMPA in rat retina was shown to affect the viability of horizontal and bNOS, ChAT, and calbindinexpressing amacrine cells, but not photoreceptors, bipolar or ganglion cells [77]. This model has been employed to investigate the neuroprotective properties of new pharmacological agents in the early events of retinal ischemia in vivo [7779]. In this paradigm of excitotoxicity, AEA and the synthetic cannabinoids HU-210 and MethAEA (nonhydrolysable analogue of AEA), intravitreally coinjected with AMPA, provided neuroprotection to bNOS and ChAT expressing amacrine cells [29]. The CB2 preferring agonist JWH015 did not display any neuroprotection. The selective inverse agonist AM251 reversed the neuroprotective actions of these agents.
This study suggested that the CB1 receptor is responsible for the neuroprotective actions of the cannabinoids. In addition, AEA afforded neuroprotection to horizontal and GABA amacrine calbindin-immunoreactive cells [29].

The involvement of $\mathrm{CB} 1$ receptor in the neuroprotective actions of the endocannabinoid 2-AG has also been investigated in the AMPA excitotoxicity model. 2-AG was intravitreally coinjected with AMPA in wild-type, CB1 and CB2 C57BL/6 knockout mice. 2-AG reversed the AMPA induced reduction of bNOS expressing amacrine cells, in both wild-type and $\mathrm{CB}^{-/-}$mice. However, 2-AG did afford neuroprotection in the CB1 knockout retinas. These results substantiated the involvement of the $\mathrm{CB} 1$ receptor in the neuroprotective actions of 2-AG against AMPA excitotoxicity in mouse retina [80].

Cannabinoids are known to activate prosurvival downstream signaling pathways in different paradigms which involve, among others, the prosurvival PI3K/Akt and the MEK/ERK1/2 signaling pathways [81-85]. In rat retina, the $\mathrm{PI} 3 \mathrm{~K} / \mathrm{Akt}$ signaling pathway was shown to be involved in the neuroprotective actions of HU-210 and AEA in the AMPA excitotoxicity model, whereas the MEK/ERK1/2 signaling pathway seemed to be involved in the neuroprotective actions of AEA, but not HU-210 [29]. Molina-Holgado et al. [86] also presented similar results reporting that HU-210 acted in a neuroprotective manner against AMPA excitotoxicity in primary cortical neuronal cultures by leading to the phosphorylation of Akt, but not ERK1/2 kinases. Moreover, MethAEA has also been shown to induce ERK1/2 phosphorylation in the hippocampus via a CB1-dependent mechanism [83].

In the in vivo IOP-reperfusion model of glaucoma, retinal ischemia-reperfusion led to an attenuation of AEA levels and this was shown to be due to the enhanced activity of its metabolic enzyme FAAH [28]. In this paradigm, a downregulation of CB1 receptors and TRPV1 channels was also reported. Administration of the FAAH inhibitor URB597 diminished the retinal damage, while intravitreal injection of MethAEA rescued RGCs via activation of CB1 receptors and TRPV1 channels [28]. This study supports that the endocannabinoid system may be involved in the loss of RGCs and that cannabinergic agents (CB1 or TRPV1 agonists and inhibitors of endocannabinoid metabolic enzymes) may be important therapeutics in glaucoma.

In the STZ animal model of diabetic retinopathy, CBD treatment provided neuroprotection, blood brain barrier preservation, and anti-inflammatory actions [87]. Thus, CBD prevented the neurodegenerative and neuroinflammatory components of diabetic retinopathy. Specifically, administration of CBD led to attenuation of proinflammatory cytokines, tumor necrosis factor $(\mathrm{TNF} \alpha)$ and VEGF, reduction of oxidative and nitrative stress, and neuroprotection to inner retinal neurons [87].

Further support for the neuroprotection afforded by the synthetic cannabinoid HU210 to retinal neurons was shown in a study by Lax et al. [88]. These investigators performed immunohistochemical and electrophysiological studies and showed that HU210 afforded neuroprotection to photoreceptor cells in a model of retinitis pigmentosa [88]. Intraperitoneal administration of HU-210 improved the disrupted 


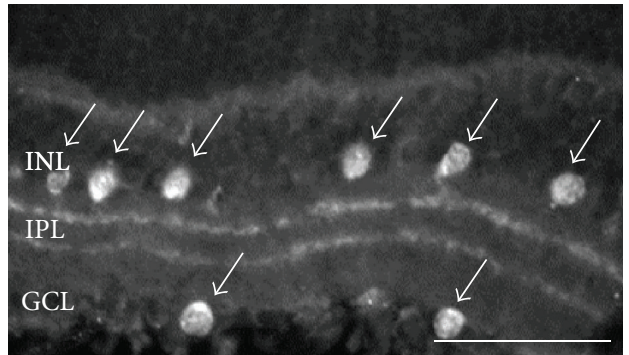

(A)

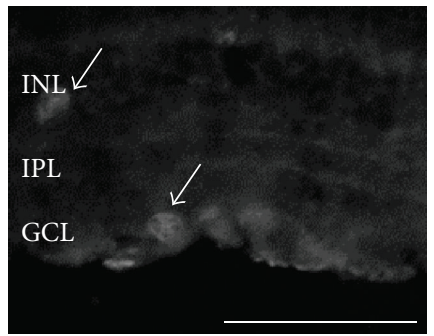

(C)

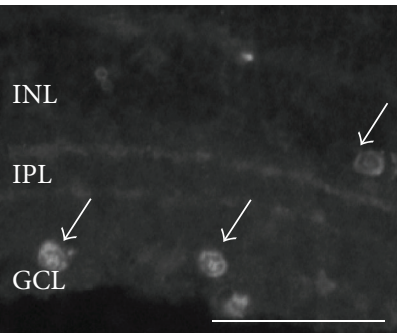

(D)

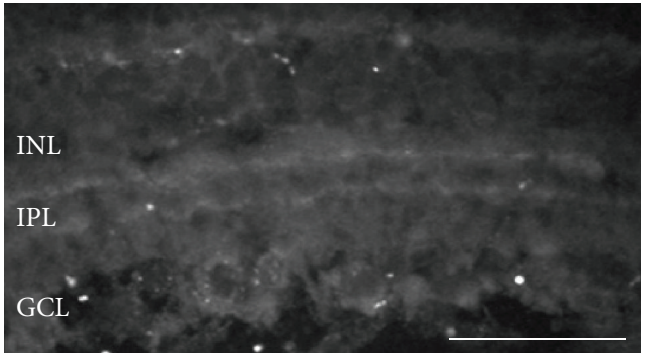

(B)

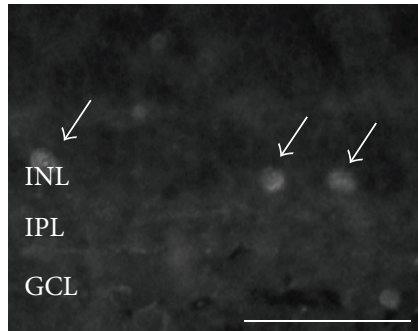

(E)

(a)

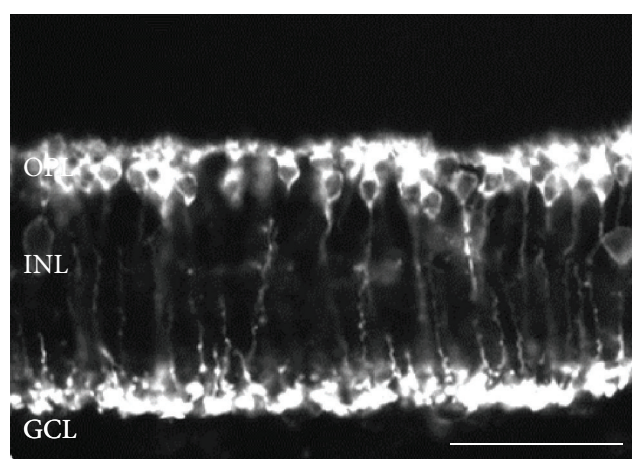

(A)

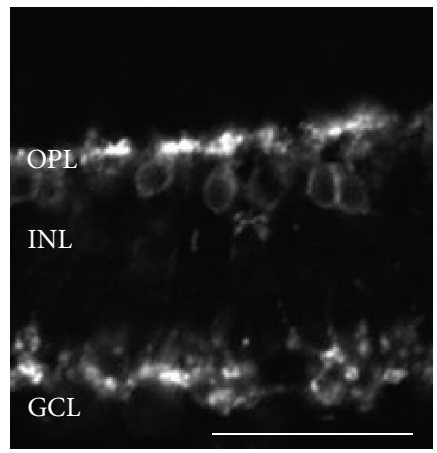

(C)

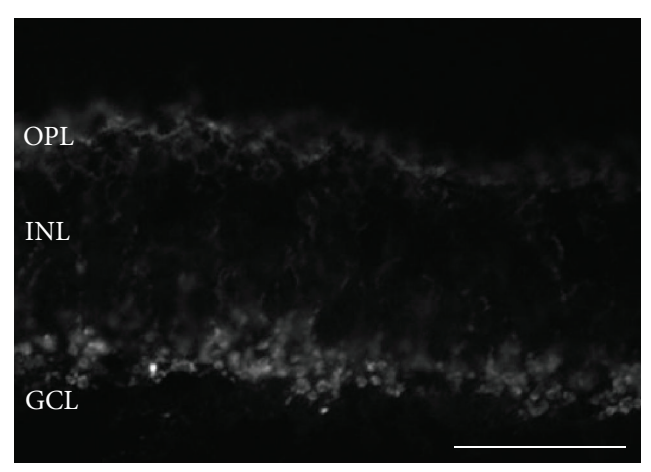

(B)

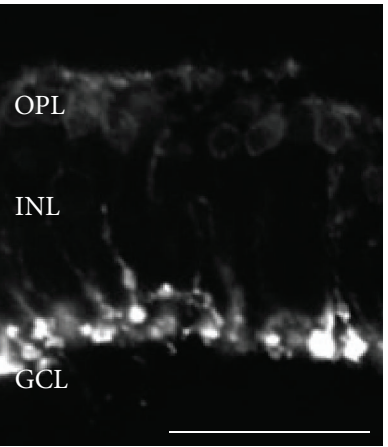

(D)

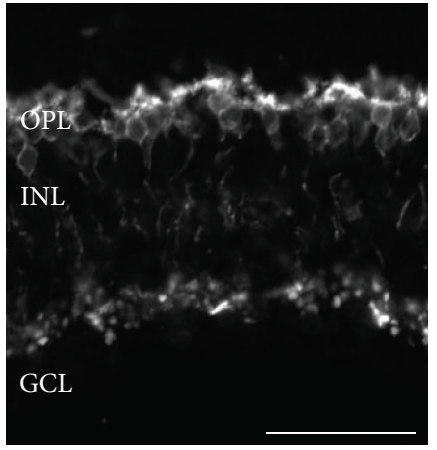

(E)

(b)

FIGURE 2: Effect of the synthetic CB1/CB2 cannabinoid HU-210 on ChAT and PKC immunoreactivity. (a) ChAT immunoreactivity. ChAT immunoreactivity in control tissue $((\mathrm{A}) n=12)$ is localized in cholinergic amacrine cell somata in the INL and GCL, as well as in their processes in the IPL. (B) Chemical ischemia mixture $(n=12)$ caused a reduction of ChAT immunoreactivity as revealed by loss of cholinergic cell somata and less intense signal in cell processes. HU-210 afforded neuroprotection at the concentrations of $10^{-6} \mathrm{M}((\mathrm{C}) n=5), 10^{-5} \mathrm{M}((\mathrm{D})$ $n=5)$, and $10^{-4} \mathrm{M}((\mathrm{E}) n=5)$. Arrows depict ChAT-immunoreactive amacrine cells. (b) PKC immunoreactivity. PKC immunoreactivity in control tissue $((\mathrm{A}) n=3)$ is localized in rod bipolar cells in the OPL and in their axons extending toward the IPL. Reduced immunoreactivity is observed in the presence of the chemical ischemia mixture $((\mathrm{B}) n=3)$. HU-210 afforded neuroprotection at all of concentrations used $\left(10^{-6} \mathrm{M}((\mathrm{C}) n=3), 10^{-5} \mathrm{M}((\mathrm{D}) n=3)\right.$, and $\left.10^{-4} \mathrm{M}((\mathrm{E}) n=3)\right)$. Scale bar: $50 \mu \mathrm{m}$. OPL: outer plexiform layer; INL: inner nuclear layer; IPL: inner plexiform layer; GCL: ganglion cell layer. 


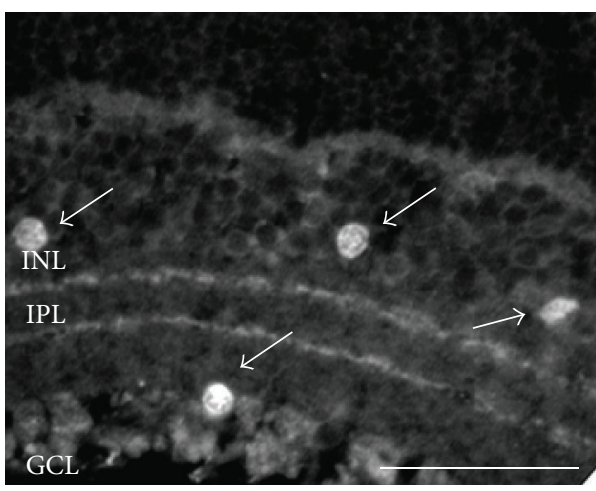

(A)

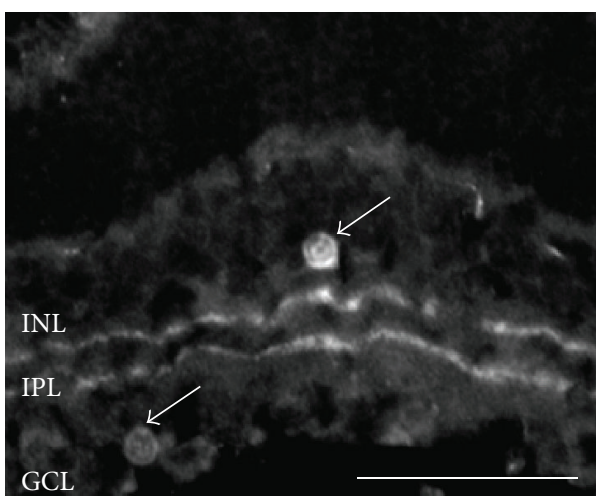

(C)

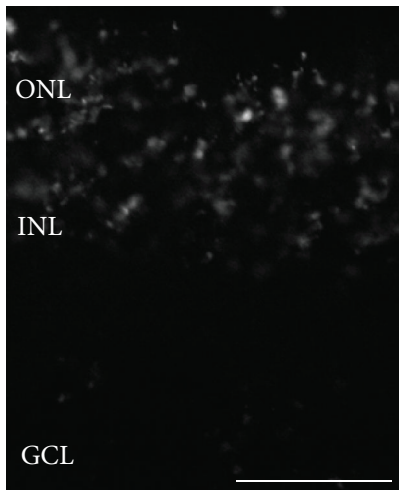

(A)

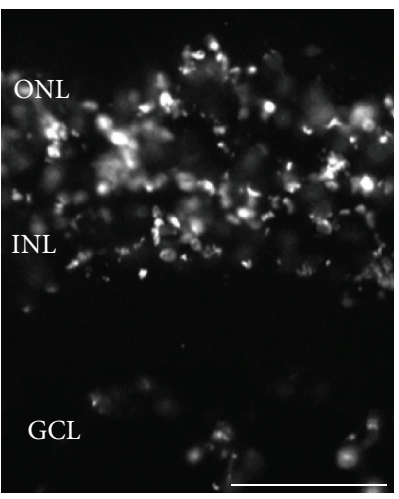

(B)

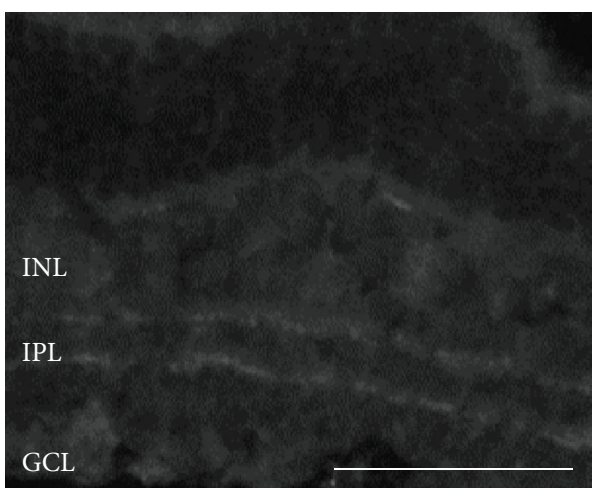

(B)

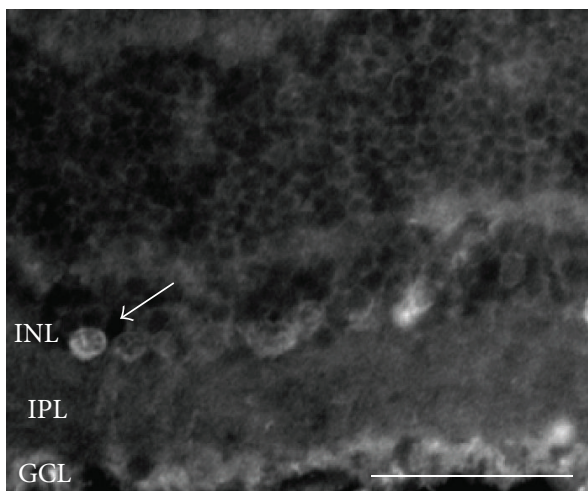

(D)

(a)

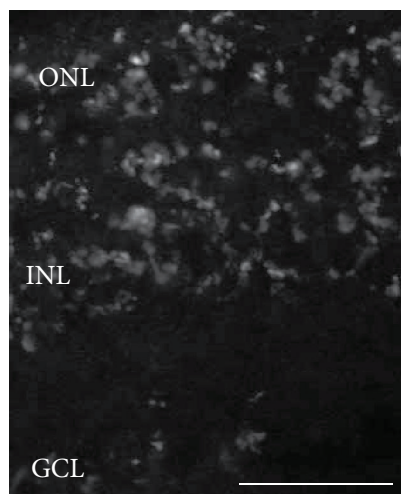

(C)

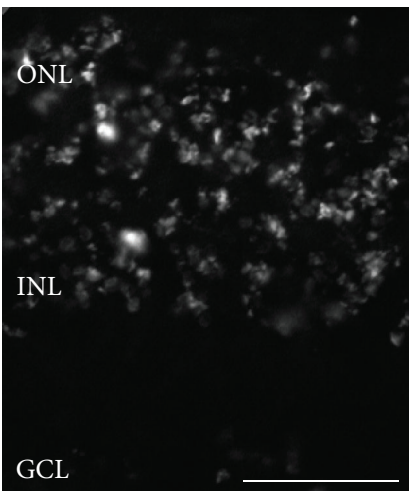

(D)

(b)

FIGURE 3: Involvement of the CB1 receptor on the neuroprotective actions of HU-210. (a) ChAT immunoreactivity. The selective inverse agonist AM251 attenuated the neuroprotective actions of HU-210 on cholinergic amacrine cells ((A) control, $n=12$; (B) chemical ischemia mixture, $n=12$; (C) HU-210 $\left(10^{-5} \mathrm{M}\right), n=3$; (D) HU-210 $\left.\left(10^{-5} \mathrm{M}\right)+\mathrm{AM} 251\left(10^{-5} \mathrm{M}\right)\right)$. Arrows depict ChAT-immunoreactive amacrine cells. Scale bar: $50 \mu \mathrm{m}$. (b) Effect of cannabinoids on retinal cell death. TUNEL staining was prominent in the chemical ischemia incubated tissues ((B) $n=2)$ while less staining was observed in the control tissues ((A) $n=2)$. TUNEL staining substantiates the neuroprotective effects of HU-210 ((C) $\left.10^{-5} \mathrm{M}, n=2\right)$ and the reduced neuroprotection (increased TUNEL staining) in the presence of AM251 ((D) $\left.10^{-5} \mathrm{M}, n=3\right)$. ONL: outer nuclear layer; INL: inner nuclear layer; IPL: inner plexiform layer; GCL: ganglion cell layer.

connectivity of photoreceptor cells with horizontal and bipolar cells and preserved the morphology and function of photoreceptors.

Cannabinoids also bind to and activate TRPV1 channels. Previous studies suggested that the TRPV1 ligand capsaicin induces degeneration of RGCs in preweanling rats [89] and apoptosis in isolated RGCs via a $\mathrm{Ca}^{2+}$-dependent mechanism [90]. However, capsaicin has been shown to protect RGCs in an in vivo model of NMDA retinal excitotoxicity in rats, via TRPV1 channel activation [91]. Intravitreal administration of 


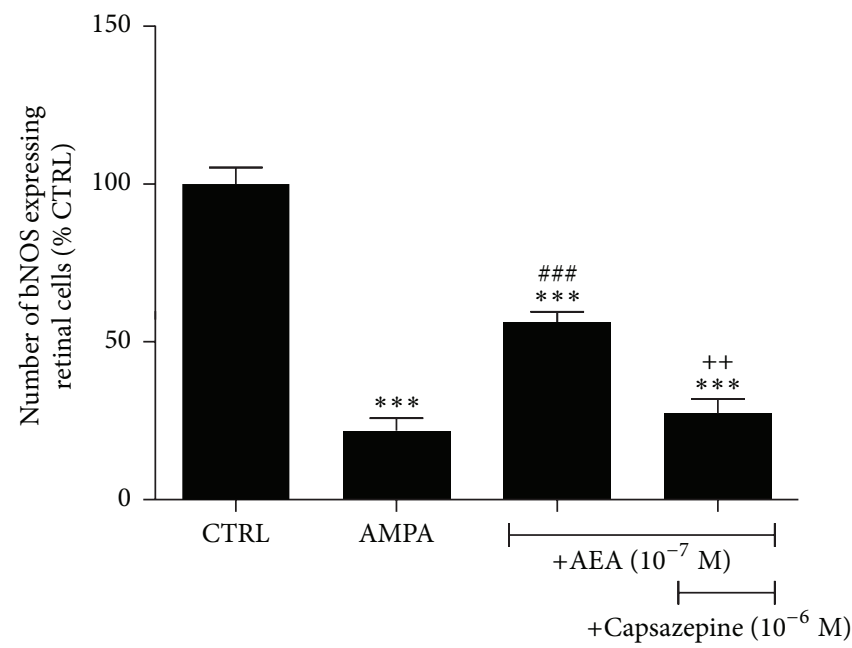

(a)

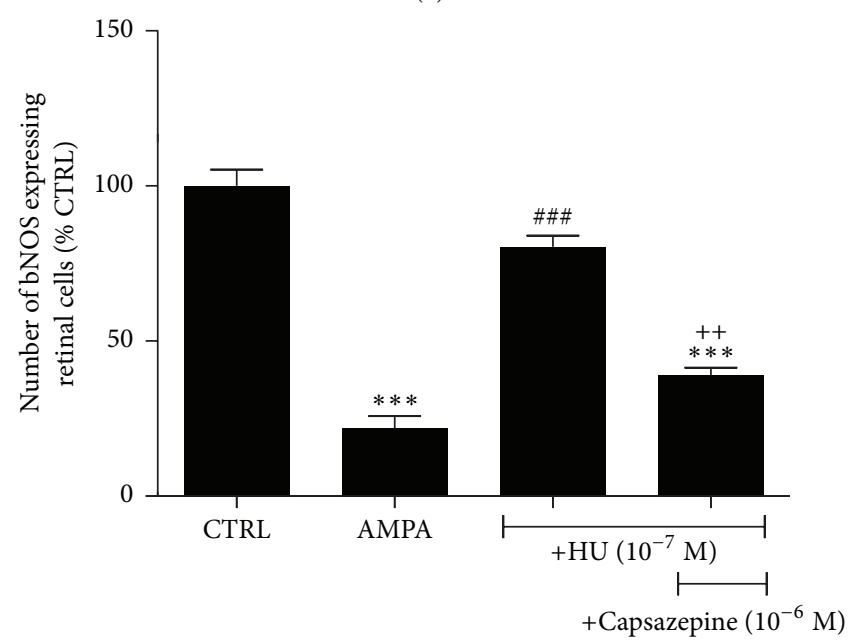

(c)

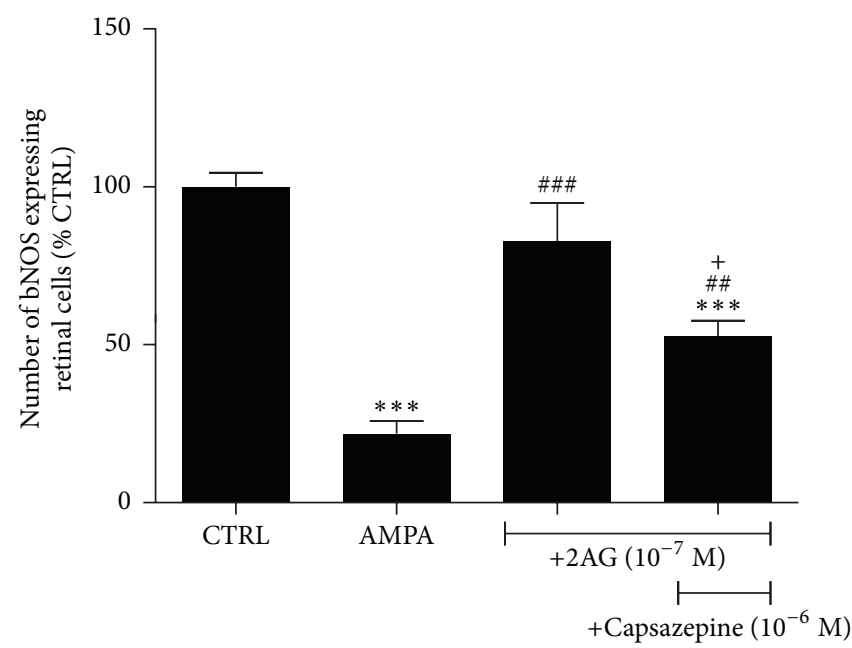

(b)

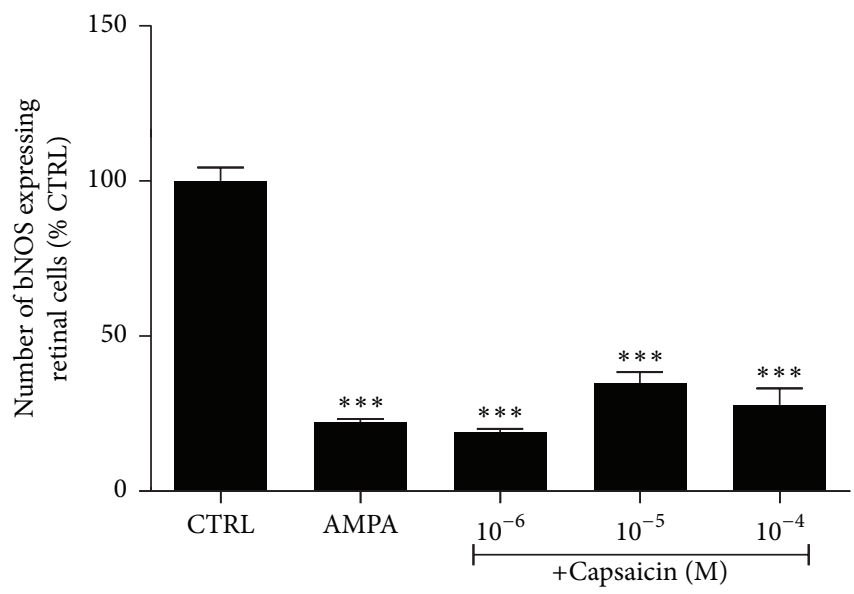

(d)

FIGURE 4: Involvement of the TRPV1 channel on the neuroprotective actions of endogenous and synthetic cannabinoids on bNOS expressing amacrine cells. (a) Intravitreal coinjection of the TRPV1 antagonist capsazepine $\left(10^{-6} \mathrm{M}\right)$ with AMPA $(42 \mathrm{nmol} / \mathrm{eye})+\mathrm{AEA}\left(10^{-7} \mathrm{M}, n=6\right)$ or 2-AG (b) $\left(10^{-7} \mathrm{M}, n=3\right)$ or HU-210 (c) $\left(10^{-7} \mathrm{M}, n=3\right)$ attenuated the neuroprotective effects of the cannabinoid ligands $\left({ }^{* * *} p<0.001\right.$ compared to CTRL, ${ }^{\# \#} p<0.01,{ }^{\# \# \#} p<0.001$ compared to AMPA, and ${ }^{+} p<0.05,{ }^{++} p<0.01$ compared to AEA (10 $\left.{ }^{-7} \mathrm{M}\right)$ or $2-\mathrm{AG}\left(10^{-7} \mathrm{M}\right)$ or HU-210 $\left(10^{-7} \mathrm{M}\right)$, resp.). (d) The TRPV1 channel agonist capsaicin $\left(10^{-6}-10^{-4} \mathrm{M}, n=3\right)$ coinjected with AMPA had no neuroprotective effect at any of the doses tested $\left({ }^{* * *} p<0.001\right.$, compared to CTRL). One-way ANOVA with Tukey's post hoc analysis was used for the statistical analysis of all data presented in this figure.

MethAEA via activation of the TRPV1 channel rescued RGCs from ischemia-reperfusion insults [28]. The involvement of the TRPV1 channel in the neuroprotective properties of AEA, 2-AG, and HU-210 was also examined in the AMPA excitotoxicity model. The TRPV1 antagonist capsazepine intravitreally administered with the above agents attenuated their neuroprotective actions on the bNOS-immunoreactive amacrine cells, suggesting a neuroprotective role for the TRPV1 channel in this paradigm (Figures 4(a)-4(c)). However, functional studies employing the TRPV1 agonist capsaicin did not show any neuroprotective effects at any of the doses used (Figure 4(d)). These results suggested that the TRPV1 channel is not localized in bNOS amacrine cells and that capsazepine's actions are independent of the TRPV1 channel.
The results presented in this part of the review provide strong evidence for the neuroprotective role of the endocannabinoids and the synthetic cannabinoids in different models of retinal disease via the activation primarily of the CB1 receptor and its signal transduction mechanisms. In Section 3.3 the interaction of the endocannabinoid system with other neuromodulatory systems in the retina will be presented in order to assess the influence of this interaction on the cannabinoid induced neuroprotection.

\subsection{Neuromodulatory Role of Cannabinoids and Neuroprotec-} tion. The CB1 receptor has been localized in photoreceptors, rod bipolar, a variety of amacrine, horizontal, and ganglion cells in retinas of many species. This was assessed by immunohistochemical studies $[10,21]$ and also confirmed from 
the functional neuroprotective roles of the endogenous and synthetic cannabinoids in the different models of retinopathy presented in this review. The localization of the CB1 receptor in each retinal neuron provided in many cases information on the mechanism involved in the neuroprotection of the agents employed.

The presence of the CB1 receptor in rod bipolar cells suggests that its activation may influence glutamate neurotransmission. WIN55,212-2 was shown to inhibit L-type calcium currents in salamander bipolar cells [10]. These channels regulate glutamate release and their inhibition will modulate in a negative manner glutamatergic transmission between the bipolar, amacrine, and ganglion cells. While release studies have not been performed on isolated rod bipolar cells, $\mathrm{CB} 1$ agonists were shown to inhibit $\mathrm{K}^{+}$and ischemia-induced $\left[{ }^{3} \mathrm{H}\right]$-D-aspartate release from isolated bovine retinas, as mentioned above [47]. A decrease in glutamate and intracellular calcium ion levels will lead to neuroprotection, since the underlying cause of excitotoxicity induced cell death is the rise in intracellular calcium levels. A possible mechanism via which HU-210 afforded neuroprotection to rod bipolar cells in the model of chemical ischemia (Figure 2) may involve the direct activation of CB1 receptors and the subsequent inhibition of calcium and glutamate levels.

A similar conjecture cannot be made as to the mechanisms via which HU-210 provided neuroprotection to ChATimmunoreactive amacrine cells. While the CB1 receptor has been localized in subpopulations of amacrine cells, its presence in ChAT expressing neurons, to our knowledge, has not been reported to date [10,21]. One cannot exclude the presence of the CB1 receptor in cholinergic neurons, yet neuroprotection may also be afforded by cannabinoids via indirect mechanisms orchestrated by the modulatory actions of cannabinoids and other neurotransmitters in the retina, as will be presented in the following.

Inhibitory neurotransmitters, such as GABA, could counteract the toxic influence of glutamate on retinal neurons during retinal ischemia and would be expected to provide neuroprotection. GABA was also suggested as a neuroprotective agent in brain acute ischemic stroke [92]. A reduction of the excitatory input or an increase of the inhibitory input in the retina can afford neuroprotection.

Dopamine (DA) is a major neuromodulator in the retina that affects retinal circuitry by activating two major families of dopamine receptors, $\mathrm{D}_{1}$ and $\mathrm{D}_{2}[93,94]$. CB1 and the dopamine inhibitory $D_{2}$ receptors are found in cones, whereas $\mathrm{CB} 1$ and the dopamine stimulatory $\mathrm{D}_{1}$ receptors are found in ON bipolar cells. A reciprocal inhibition of voltagegated potassium currents $\left(I \mathrm{~K}_{(V)}\right)$ by activation of cannabinoid $\mathrm{CB} 1$ and dopamine $\mathrm{D}_{1}$ receptors in ON bipolar cells of goldfish retina was reported [46]. These findings support an antagonistic interaction between the cannabinoid and dopamine signaling that may influence transmitter release. In addition, it was proposed that endocannabinoids function as a scotopic signal, interacting with dopamine to set retinal sensitivity.

DA also regulates the release of other retinal neuromodulators, such as NO (nitric oxide) and the neuropeptide somatostatin. It enhances $\mathrm{NO}$ release, while a reciprocal effect was also observed, namely, NO attenuating DA release [9597]. NO, cGMP, and the NO donor SIN-1 stimulated the release of GABA in the retina [98]. Somatostatin was also shown to influence the release of both dopamine and $\mathrm{NO}$ in the retina $[99,100]$. DA, via $\mathrm{D}_{1}$ receptor activation, and NO, via guanylyl cyclase and cGMP, influence somatostatin levels in the retina. These results suggested that the triad of neuromodulators, somatostatin-dopamine-NO, have reciprocal interactions via which they regulate retinal circuitry [101]. CB1 agonists were also shown to inhibit the release of retinal $\left[{ }^{3} \mathrm{H}\right]$ dopamine [48]. HU-210 regulated somatostatin release in a bimodal manner (Figure 1(a)), in agreement with what was reported for cannabinoid effects on GABA release in the globus pallidus [102]. Therefore, it appears that the interactions amongst transmitter and neuromodulator systems in the retina not only regulate retinal circuitry, retinal sensitivity, and light adaptation but may also provide the neuroprotective mechanisms involved in reducing ischemiadependent toxicity. It is possible that cannabinoid interactions with other retinal modulatory systems may lead to the indirect neuroprotection of retinal neurons.

However, other mechanisms may also be involved. HU210 was shown to provide neuroprotection and counteract the oxidative stress and cellular injuries observed in diabetic encephalopathy, a CNS neuropathy and one of the most common complications of diabetes, through a cannabinoid receptor-independent mechanism [94].

\section{Concluding Remarks}

The aim of this review was to summarize the knowledge acquired to date on the function of endogenous and synthetic cannabinoids in the retina, the receptors they activate to mediate their actions, and the neuroprotective role of cannabinoids in retinal models of disease. The studies presented in this review support the involvement of the endocannabinoids, AEA and 2-AG, and synthetic cannabinoids in the neuroprotection of the early and final events underlying the pathophysiology of retinal ischemia. It appears that these agents have the pharmacological profile to target the neurodegenerative/proapoptotic components of retinal disease.

The available treatments for neurodegenerative retinal diseases have limitations and further research is needed in order to provide efficacious therapies. Cannabinergic agents, CB1 or TRPV1 agonists and inhibitors of endocannabinoid metabolic enzymes, may prove to be efficacious therapeutics in the treatment of glaucoma and diabetic retinopathy.

In order to provide "LEAD" cannabinergic agents, further studies are essential (a) to study the pharmacokinetic properties of cannabinoids that would suggest their use as effective topical retinal therapies and (b) to ascertain their pharmacological efficacy in chronic use. These studies will assess whether cannabinergic agents can play an important role alone or in a multidrug treatment to provide efficacious therapy and improve the eye sight of millions of people worldwide who are afflicted with neurodegenerative retinal disease. 
Abbreviations

\begin{tabular}{|c|c|}
\hline 2-AG: & 2-Arachidonoylglycerol \\
\hline ACEA: & Arachidonyl-2'-chloroethylamide \\
\hline AEA: & Arachidonoyl ethanolamide \\
\hline AMPA: & $\begin{array}{l}\alpha \text {-Amino-3-hydroxy-5-methyl- } 4 \\
\text { isoxazolepropionic acid }\end{array}$ \\
\hline bNOS: & Brain nitric oxide synthase \\
\hline CB1: & Cannabinoid receptor 1 \\
\hline CB2: & Cannabinoid receptor 2 \\
\hline CBD: & Cannabidiol \\
\hline cGMP: & Cyclic guanosine monophosphate \\
\hline ChAT: & Choline acetyl transferase \\
\hline CNS: & Central nervous system \\
\hline DAGL: & Diacylglycerol lipase \\
\hline ERK1/2: & $\begin{array}{l}\text { Extracellular signal-regulated } \\
\text { kinases } 1 / 2\end{array}$ \\
\hline FAAH: & Fatty acid amide hydrolase \\
\hline GABA: & Gamma-aminobutyric acid \\
\hline GCL: & Ganglion cell layer \\
\hline INL: & Inner nuclear layer \\
\hline IOP: & Intraocular pressure \\
\hline IPL: & Inner plexiform layer \\
\hline MethAEA: & Methanandamide \\
\hline MGL: & Monoacylglycerol lipase \\
\hline NAPE-PLD: & $\begin{array}{l}\text { N-Acyl phosphatidylethanolamine } \\
\text { phospholipase D }\end{array}$ \\
\hline NMDA: & N-Methyl-D-aspartate \\
\hline$\Delta^{9}-\mathrm{THC}:$ & $\Delta^{9}$-Tetrahydroxycannabinol \\
\hline NO: & Nitric oxide \\
\hline ONL: & Outer nuclear layer \\
\hline OPL: & Outer plexiform layer \\
\hline PKC: & Protein kinase $\mathrm{C}$ \\
\hline RGC: & Retinal ganglion cell \\
\hline SAPK/JNK: & $\begin{array}{l}\text { Stress-activated protein kinase/c-Jun } \\
\text { N-terminal }\end{array}$ \\
\hline STZ: & Streptozotocin \\
\hline TH: & Tyrosine hydroxylase \\
\hline TRPV1: & $\begin{array}{l}\text { Transient receptor potential cation } \\
\text { channel subfamily V member } 1\end{array}$ \\
\hline TUNEL: & $\begin{array}{l}\text { Terminal deoxynucleotidyl transferase } \\
\text { (TdT) dUTP nick-end labeling }\end{array}$ \\
\hline VEGF: & Vascular endothelial growth factor. \\
\hline
\end{tabular}

\section{Conflict of Interests}

The authors declare that there is no conflict of interests regarding the publication of this review.

\section{Acknowledgments}

Grants to Kyriaki Thermos that supported the studies presented in this review were funded from the European Social Fund and Greek National Funds through the Operational Program "Education and Lifelong Learning" of the National Strategic Reference Framework-Research Funding Program: Herakleitus II and PENED.

\section{References}

[1] S. Yazulla, "Endocannabinoids in the retina: from marijuana to neuroprotection," Progress in Retinal and Eye Research, vol. 27, no. 5, pp. 501-526, 2008.

[2] T. Schwitzer, R. Schwan, K. Angioi-Duprez et al., "The cannabinoid system and visual processing: a review on experimental findings and clinical presumptions," European Neuropsychopharmacology, vol. 25, no. 1, pp. 100-112, 2014.

[3] R. S. Hepler and I. R. Frank, "Marihuana smoking and intraocular pressure," Journal of the American Medical Association, vol. 217, no. 10 , p. $1392,1971$.

[4] J. C. Merritt, D. D. Perry, D. N. Russell, and B. F. Jones, “Topical delta 9-tetrahydrocannabinol and aqueous dynamics in glaucoma," Journal of Clinical Pharmacology, vol. 21, no. 8-9, supplement, pp. 467S-471S, 1981.

[5] T. Järvinen, D. W. Pate, and K. Laine, "Cannabinoids in the treatment of glaucoma," Pharmacology \& Therapeutics, vol. 95, no. 2, pp. 203-220, 2002.

[6] I. Tomida, R. G. Perlwee, and A. Azuara-Blanco, "Cannabinoids and glaucoma," British Journal of Ophthalmology, vol. 88, no. 5, pp. 708-713, 2004.

[7] W. A. Devane, L. Hanus, A. Breuer et al., "Isolation and structure of a brain constituent that binds to the cannabinoid receptor," Science, vol. 258, no. 5090, pp. 1946-1949, 1992.

[8] S. Matsuda, N. Kanemitsu, A. Nakamura et al., "Metabolism of anandamide, an endogenous cannabinoid receptor ligand, in porcine ocular tissues," Experimental Eye Research, vol. 64, no. 5, pp. 707-711, 1997.

[9] T. Bisogno, I. Delton-Vandenbroucke, A. Milone, M. Lagarde, and V. Di Marzo, "Biosynthesis and inactivation of $\mathrm{N}$-arachidonoylethanolamine (anandamide) and $\mathrm{N}$-docosahexaenoylethanolamine in bovine retina," Archives of Biochemistry and Biophysics, vol. 370, no. 2, pp. 300-307, 1999.

[10] A. Straiker, N. Stella, D. Piomelli, K. Mackie, H. J. Karten, and G. Maguire, "Cannabinoid CB1 receptors and ligands in vertebrate retina: localization and function of an endogenous signaling system," Proceedings of the National Academy of Sciences of the United States of America, vol. 96, no. 25, pp. 14565-14570, 1999.

[11] W. A. Devane, F. A. Dysarz III, M. R. Johnson, L. S. Melvin, and A. C. Howlett, "Determination and characterization of a cannabinoid receptor in rat brain," Molecular Pharmacology, vol. 34, no. 5, pp. 605-613, 1988.

[12] L. A. Matsuda, S. J. Lolait, M. J. Brownstein, A. C. Young, and T. I. Bonner, "Structure of a cannabinoid receptor and functional expression of the cloned cDNA," Nature, vol. 346, no. 6284, pp. 561-564, 1990.

[13] M. Herkenham, A. B. Lynn, M. R. Johnson, L. S. Melvin, B. R. de Costa, and K. C. Rice, "Characterization and localization of cannabinoid receptors in rat brain: a quantitative in vitro autoradiographic study," The Journal of Neuroscience, vol. 11, no. 2, pp. 563-583, 1991.

[14] S. Munro, K. L. Thomas, and M. Abu-Shaar, "Molecular characterization of a peripheral receptor for cannabinoids," Nature, vol. 365, no. 6441, pp. 61-65, 1993.

[15] N. E. Buckley, S. Hansson, G. Harta, and É. Mezey, "Expression of the $\mathrm{CB}_{1}$ and $\mathrm{CB}_{2}$ receptor messenger RNAs during embryonic development in the rat," Neuroscience, vol. 82, no. 4, pp. 1131-1149, 1997. 
[16] M. A. Dasilva, K. L. Grieve, J. Cudeiro, and C. Rivadulla, "Endocannabinoid CB1 receptors modulate visual output from the thalamus," Psychopharmacology, vol. 219, no. 3, pp. 835-845, 2012.

[17] I. E. Ohiorhenuan, F. Mechler, K. P. Purpura, A. M. Schmid, Q. Hu, and J. D. Victor, "Cannabinoid neuromodulation in the adult early visual cortex," PLoS ONE, vol. 9, no. 2, Article ID e87362, 2014.

[18] P. Javadi, J. Bouskila, J.-F. Bouchard, and M. Ptito, “The endocannabinoid system within the dorsal lateral geniculate nucleus of the vervet monkey," Neuroscience, vol. 288, pp. 135-144, 2015.

[19] Q. Lu, A. Straiker, Q. Lu, and G. Maguire, "Expression of CB2 cannabinoid receptor mRNA in adult rat retina," Visual Neuroscience, vol. 17, no. 1, pp. 91-95, 2000.

[20] E. S. Onaivi, H. Ishiguro, J.-P. Gong et al., "Discovery of the presence and functional expression of cannabinoid CB2 receptors in brain," Annals of the New York Academy of Sciences, vol. 1074, pp. 514-536, 2006.

[21] S. Yazulla, K. M. Studholme, H. H. McIntosh, and D. G. Deutsch, "Immunocytochemical localization of cannabinoid CB1 receptor and fatty acid amide hydrolase in rat retina," Journal of Comparative Neurology, vol. 415, no. 1, pp. 80-90, 1999.

[22] S. S.-J. Hu, A. Arnold, J. M. Hutchens et al., "Architecture of cannabinoid signaling in mouse retina," Journal of Comparative Neurology, vol. 518, no. 18, pp. 3848-3866, 2010.

[23] Q. Lu, A. Straiker, Q. Lu, and G. Maguire, "Expression of CB2 cannabinoid receptor mRNA in adult rat retina," Visual Neuroscience, vol. 17, no. 1, pp. 91-95, 2000.

[24] Y. Wei, X. Wang, and L. Wang, "Presence and regulation of cannabinoid receptors in human retinal pigment epithelial cells," Molecular Vision, vol. 15, pp. 1243-1251, 2009.

[25] E. M. López, P. Tagliaferro, E. S. Onaivi, and J. J. López-Costa, "Distribution of CB2 cannabinoid receptor in adult rat retina," Synapse, vol. 65, no. 5, pp. 388-392, 2011.

[26] B. Cécyre, N. Zabouri, F. Huppé-Gourgues, J.-F. Bouchard, and C. Casanova, "Roles of cannabinoid receptors type 1 and 2 on the retinal function of adult mice," Investigative Ophthalmology \& Visual Science, vol. 54, no. 13, pp. 8079-8090, 2013.

[27] J. Bouskila, P. Javadi, C. Casanova, M. Ptito, and J.-F. Bouchard, "Müller cells express the cannabinoid CB2 receptor in the vervet monkey retina," Journal of Comparative Neurology, vol. 521, no. 11, pp. 2399-2415, 2013.

[28] C. Nucci, V. Gasperi, R. Tartaglione et al., "Involvement of the endocannabinoid system in retinal damage after high intraocular pressure-induced ischemia in rats," Investigative Ophthalmology \& Visual Science, vol. 48, no. 7, pp. 2997-3004, 2007.

[29] D. Kokona and K. Thermos, "Synthetic and endogenous cannabinoids protect retinal neurons from AMPA excitotoxicity in vivo, via activation of CB1 receptors: involvement of PI3K/Akt and MEK/ERK signaling pathways," Experimental Eye Research, vol. 136, pp. 45-58, 2015.

[30] L. Iversen and V. Chapman, "Cannabinoids: a real prospect for pain relief?" Current Opinion in Pharmacology, vol. 2, no. 1, pp. 50-55, 2002.

[31] R. G. Pertwee and R. A. Ross, "Cannabinoid receptors and their ligands," Prostaglandins Leukotrienes and Essential Fatty Acids, vol. 66, no. 2-3, pp. 101-121, 2002.

[32] E. Ryberg, N. Larsson, S. Sjögren et al., "The orphan receptor GPR55 is a novel cannabinoid receptor," British Journal of Pharmacology, vol. 152, no. 7, pp. 1092-1101, 2007.
[33] M. Leonelli, D. O. Martins, A. H. Kihara, and L. R. Britto, “Ontogenetic expression of the vanilloid receptors TRPV1 and TRPV2 in the rat retina," International Journal of Developmental Neuroscience, vol. 27, no. 7, pp. 709-718, 2009.

[34] J. Bouskila, P. Javadi, C. Casanova, M. Ptito, and J.-F. Bouchard, "Rod photoreceptors express GPR55 in the adult vervet monkey retina," PLoS ONE, vol. 8, no. 11, Article ID e81080, 2013.

[35] A. C. Howlett and R. M. Fleming, "Cannabinoid inhibition of adenylate cyclase. Pharmacology of the response in neuroblastoma cell membranes," Molecular Pharmacology, vol. 26, no. 3, pp. 532-538, 1984.

[36] D. J. Henry and C. Chavkin, "Activation of inwardly rectifying potassium channels (GIRK1) by co-expressed rat brain cannabinoid receptors in Xenopus oocytes," Neuroscience Letters, vol. 186, no. 2-3, pp. 91-94, 1995.

[37] K. Mackie, Y. Lai, R. Westenbroek, and R. Mitchell, "Cannabinoids activate an inwardly rectifying potassium conductance and inhibit Q-type calcium currents in AtT20 cells transfected with rat brain cannabinoid receptor," The Journal of Neuroscience, vol. 15, no. 10, pp. 6552-6561, 1995.

[38] M. P. Caulfield and D. A. Brown, "Cannabinoid receptor agonists inhibit Ca current in NG108-15 neuroblastoma cells via a pertussis toxin-sensitive mechanism," British Journal of Pharmacology, vol. 106, no. 2, pp. 231-232, 1992.

[39] K. Macki and B. Hille, "Cannabinoids inhibit N-type calcium channels in neuroblastoma-glioma cells," Proceedings of the National Academy of Sciences of the United States of America, vol. 89, no. 9, pp. 3825-3829, 1992.

[40] N. Zabouri, J.-F. Bouchard, and C. Casanova, "Cannabinoid receptor type 1 expression during postnatal development of the rat retina," The Journal of Comparative Neurology, vol. 519, no. 7, pp. 1258-1280, 2011.

[41] D. G. Deutsch and S. A. Chin, "Enzymatic synthesis and degradation of anandamide, a cannabinoid receptor agonist," Biochemical Pharmacology, vol. 46, no. 5, pp. 791-796, 1993.

[42] J. L. Blankman, G. M. Simon, and B. F. Cravatt, "A comprehensive profile of brain enzymes that hydrolyze the endocannabinoid 2-arachidonoylglycerol," Chemistry \& Biology, vol. 14, no. 12, pp. 1347-1356, 2007.

[43] J. R. Savinainen and J. T. Laitinen, "Detection of cannabinoid $C_{1}$, adenosine $A_{1}$, muscarinic acetylcholine, and $G_{A B A}$ receptor-dependent $G$ protein activity in transducin-deactivated membranes and autoradiography sections of rat retina," Cellular and Molecular Neurobiology, vol. 24, no. 2, pp. 243-256, 2004.

[44] A. Straiker and J. M. Sullivan, "Cannabinoid receptor activation differentially modulates ion channels in photoreceptors of the tiger salamander," Journal of Neurophysiology, vol. 89, no. 5, pp. 2647-2654, 2003.

[45] S.-F. Fan and S. Yazulla, "Biphasic modulation of voltagedependent currents of retinal cones by cannabinoid CB1 receptor agonist WIN 55212-2," Visual Neuroscience, vol. 20, no. 2, pp. 177-188, 2003.

[46] S.-F. Fan and S. Yazulla, "Reciprocal inhibition of voltage-gated potassium currents $\left(I_{\mathrm{K}(\mathrm{V})}\right)$ by activation of cannabinoid $\mathrm{CB}_{1}$ and dopamine $\mathrm{D}_{1}$ receptors in ON bipolar cells of goldfish retina," Visual Neuroscience, vol. 22, no. 1, pp. 55-63, 2005.

[47] C. A. Opere, W. D. Zheng, M. Zhao, J. S. Lee, K. Kulkarni, and S. E. Ohia, "Inhibition of potassium- and ischemia-evoked $[3 \mathrm{H}]$ $\mathrm{D}$-aspartate release from isolated bovine retina by cannabinoids," Current Eye Research, vol. 31, no. 7-8, pp. 645-653, 2006. 
[48] E. Schlicker, J. Timm, and M. Göthert, "Cannabinoid receptormediated inhibition of dopamine release in the retina," NaunynSchmiedeberg's Archives of Pharmacology, vol. 354, no. 6, pp. 791795, 1996.

[49] B. Weber and E. Schlicker, "Modulation of dopamine release in the guinea-pig retina by $\mathrm{G}_{\mathrm{i}}$ - but not by $\mathrm{G}_{\mathrm{s}}$ - or $\mathrm{G}_{\mathrm{q}}$-proteincoupled receptors," Fundamental \& Clinical Pharmacology, vol. 15, no. 6, pp. 393-400, 2001.

[50] A. Warrier and M. Wilson, "Endocannabinoid signaling regulates spontaneous transmitter release from embryonic retinal amacrine cells," Visual Neuroscience, vol. 24, no. 1, pp. 25-35, 2007.

[51] R. M. Sappington, T. Sidorova, N. J. Ward, R. Chakravarthy, K. W. Ho, and D. J. Calkins, "Activation of transient receptor potential vanilloid-1 (TRPV1) influences how retinal ganglion cell neurons respond to pressure-related stress," Channels, vol. 9, no. 2, pp. 102-113, 2015.

[52] S. Resnikoff, D. Pascolini, D. Etyaale et al., "Global data on visual impairment in the year 2002," Bulletin of the World Health Organization, vol. 82, no. 11, pp. 844-851, 2004.

[53] A. Porcella, P. Casellas, G. L. Gessa, and L. Pani, "Cannabinoid receptor $\mathrm{CB1}$ mRNA is highly expressed in the rat ciliary body: implications for the antiglaucoma properties of marihuana," Molecular Brain Research, vol. 58, no. 1-2, pp. 240-245, 1998.

[54] A. J. Straiker, G. Maguire, K. Mackie, and J. Lindsey, "Localization of cannabinoid CB1 receptors in the human anterior eye and retina," Investigative Ophthalmology \& Visual Science, vol. 40, no. 10, pp. 2442-2448, 1999.

[55] B. T. McIntosh, B. Hudson, S. Yegorova, C. A. B. Jollimore, and M. E. M. Kelly, "Agonist-dependent cannabinoid receptor signalling in human trabecular meshwork cells," British Journal of Pharmacology, vol. 152, no. 7, pp. 1111-1120, 2007.

[56] N. N. Osborne, M. Ugarte, M. Chao et al., "Neuroprotection in relation to retinal ischemia and relevance to glaucoma," Survey of Ophthalmology, vol. 43, supplement 1, pp. S102-S128, 1999.

[57] H. A. Quigley, "Neuronal death in glaucoma," Progress in Retinal and Eye Research, vol. 18, no. 1, pp. 39-57, 1999.

[58] M. Schwartz and E. Yoles, "Neuroprotection: a new treatment modality for glaucoma?" Current Opinion in Ophthalmology, vol. 11, no. 2, pp. 107-111, 2000.

[59] R. S. Harwerth and H. A. Quigley, "Visual field defects and retinal ganglion cell losses in patients with glaucoma," Archives of Ophthalmology, vol. 124, no. 6, pp. 853-859, 2006.

[60] E. B. Dreyer and C. L. Grosskreutz, "Excitatory mechanisms in retinal ganglion cell death in primary open angle glaucoma (POAG)," Clinical Neuroscience, vol. 4, no. 5, pp. 270-273, 1997.

[61] C. Nucci, R. Tartaglione, L. Rombolà, L. A. Morrone, E. Fazzi, and G. Bagetta, "Neurochemical evidence to implicate elevated glutamate in the mechanisms of high intraocular pressure (IOP)-induced retinal ganglion cell death in rat," Neurotoxicology, vol. 26, no. 5, pp. 935-941, 2005.

[62] D. A. Antonetti, A. J. Barber, S. K. Bronson et al., "Diabetic retinopathy: seeing beyond glucose-induced microvascular disease," Diabetes, vol. 55, no. 9, pp. 2401-2411, 2006.

[63] G. Ghirlanda, M. A. S. Di Leo, S. Caputo, S. Cercone, and A. V. Greco, "From functional to microvascular abnormalities in early diabetic retinopathy," Diabetes/Metabolism Reviews, vol. 13, no. 1, pp. 15-35, 1997.

[64] V. Parisi and L. Uccioli, "Visual electrophysiological responses in persons with type 1 diabetes," Diabetes/Metabolism Research and Reviews, vol. 17, no. 1, pp. 12-18, 2001.
[65] M. A. Bearse Jr., Y. Han, M. E. Schneck, S. Barez, C. Jacobsen, and A. J. Adams, "Local multifocal oscillatory potential abnormalities in diabetes and early diabetic retinopathy," Investigative Ophthalmology \& Visual Science, vol. 45, no. 9, pp. 3259-3265, 2004.

[66] A. J. Barber, E. Lieth, S. A. Khin, D. A. Antonetti, A. G. Buchanan, and T. W. Gardner, "Neural apoptosis in the retina during experimental and human diabetes. Early onset and effect of insulin," The Journal of Clinical Investigation, vol. 102, no. 4, pp. 783-791, 1998.

[67] V. Asnaghi, C. Gerhardinger, T. Hoehn, A. Adeboje, and M. Lorenzi, "A role for the polyol pathway in the early neuroretinal apoptosis and glial changes induced by diabetes in the rat," Diabetes, vol. 52, no. 2, pp. 506-511, 2003.

[68] T. K. Ali, S. Matragoon, B. A. Pillai, G. I. Liou, and A. B. ElRemessy, "Peroxynitrite mediates retinal neurodegeneration by inhibiting nerve growth factor survival signaling in experimental and human diabetes," Diabetes, vol. 57, no. 4, pp. 889-898, 2008.

[69] N. N. Osborne, R. J. Casson, J. P. M. Wood, G. Chidlow, M. Graham, and J. Melena, "Retinal ischemia: mechanisms of damage and potential therapeutic strategies," Progress in Retinal and Eye Research, vol. 23, no. 1, pp. 91-147, 2004.

[70] N. Ferrara, L. Damico, N. Shams, H. Lowman, and R. Kim, "Development of ranibizumab, an anti-vascular endothelial growth factor antigen binding fragment, as therapy for neovascular age-related macular degeneration," Retina, vol. 26, no. 8 , pp. 859-870, 2006.

[71] S. G. Schwartz, H. W. Flynn Jr., and I. U. Scott, "Emerging drugs for diabetic macular edema," Expert Opinion on Emerging Drugs, vol. 19, no. 3, pp. 397-405, 2014.

[72] M. K. Schmid, L. M. Bachmann, L. Fäs, A. G. Kessels, O. M. Job, and M. A. Thiel, "Efficacy and adverse events of aflibercept, ranibizumab and bevacizumab in age-related macular degeneration: a trade-off analysis," British Journal of Ophthalmology, vol. 99, no. 2, pp. 141-146, 2015.

[73] A. Vasilaki and K. Thermos, "Somatostatin analogues as therapeutics in retinal disease," Pharmacology \& Therapeutics, vol. 122, no. 3, pp. 324-333, 2009.

[74] P. B. Reiner, A. G. Laycock, and C. J. Doll, "A pharmacological model of ischemia in the hippocampal slice," Neuroscience Letters, vol. 119, no. 2, pp. 175-178, 1990.

[75] N. Mastrodimou, G. N. Lambrou, and K. Thermos, "Effect of somatostatin analogues on chemically induced ischaemia in the rat retina," Naunyn-Schmiedeberg's Archives of Pharmacology, vol. 371, no. 1, pp. 44-53, 2005.

[76] A. B. El-Remessy, I. E. Khalil, S. Matragoon et al., "Neuroprotective effect of $(-) \Delta 9$-tetrahydrocannabinol and cannabidiol in $\mathrm{N}$-methyl-D-aspartate-induced retinal neurotoxicity: involvement of peroxynitrite," American Journal of Pathology, vol. 163, no. 5, pp. 1997-2008, 2003.

[77] F. Kiagiadaki and K. Thermos, "Effect of intravitreal administration of somatostatin and $s_{2}$ analogs on AMPA-induced neurotoxicity in rat retina," Investigative Ophthalmology \& Visual Science, vol. 49, no. 7, pp. 3080-3089, 2008.

[78] F. Kiagiadaki, M. Savvaki, and K. Thermos, "Activation of somatostatin receptor (sst5) protects the rat retina from AMPAinduced neurotoxicity," Neuropharmacology, vol. 58, no. 1, pp. 297-303, 2010. 
[79] D. Kokona, I. Charalampopoulos, I. Pediaditakis, A. Gravanis, and K. Thermos, "The neurosteroid dehydroepiandrosterone (DHEA) protects the retina from AMPA-induced excitotoxicity: NGF TrkA receptor involvement," Neuropharmacology, vol. 62, no. 5-6, pp. 2106-2117, 2012.

[80] D. Kokona, A. Zimmer, and K. Thermos, "2-Arachidonoylglycerol protects the retina from AMPA excitotoxicity in vivo via the activation of $\mathrm{CB} 1$ receptor. Involvement of the PI3K/Akt signaling pathway," in Proceedings of the Neuroscience Abstracts, Society for Neuroscience, Washington, DC, USA, November 2014.

[81] T. Gómez del Pulgar, G. Velasco, and M. Guzmán, “The CB1 cannabinoid receptor is coupled to the activation of protein kinase B/Akt," Biochemical Journal, vol. 347, no. 2, pp. 369-373, 2000.

[82] A. Ozaita, E. Puighermanal, and R. Maldonado, "Regulation of PI3K/Akt/GSK-3 pathway by cannabinoids in the brain," Journal of Neurochemistry, vol. 102, no. 4, pp. 1105-1114, 2007.

[83] D. A. Karanian, Q. B. Brown, A. Makriyannis, and B. A. Bahr, "Blocking cannabinoid activation of FAK and ERK1/2 compromises synaptic integrity in hippocampus," European Journal of Pharmacology, vol. 508, no. 1-3, pp. 47-56, 2005.

[84] D. A. Karanian, Q. B. Brown, A. Makriyannis, T. A. Kosten, and B. A. Bahr, "Dual modulation of endocannabinoid transport and fatty acid amide hydrolase protects against excitotoxicity," The Journal of Neuroscience, vol. 25, no. 34, pp. 7813-7820, 2005.

[85] M. Wartmann, D. Campbell, A. Subramanian, S. H. Burstein, and R. J. Davis, "The MAP kinase signal transduction pathway is activated by the endogenous cannabinoid anandamide," FEBS Letters, vol. 359, no. 2-3, pp. 133-136, 1995.

[86] F. Molina-Holgado, E. Pinteaux, L. Heenan, J. D. Moore, N. J. Rothwell, and R. M. Gibson, "Neuroprotective effects of the synthetic cannabinoid HU-210 in primary cortical neurons are mediated by phosphatidylinositol 3-kinase/AKT signaling," Molecular and Cellular Neuroscience, vol. 28, no. 1, pp. 189-194, 2005.

[87] A. B. El-Remessy, M. Al-Shabrawey, Y. Khalifa, N.-T. Tsai, R. B. Caldwell, and G. I. Liou, "Neuroprotective and bloodretinal barrier-preserving effects of cannabidiol in experimental diabetes," American Journal of Pathology, vol. 168, no. 1, pp. 235244, 2006.

[88] P. Lax, G. Esquiva, C. Altavilla, and N. Cuenca, "Neuroprotective effects of the cannabinoid agonist HU210 on retinal degeneration," Experimental Eye Research, vol. 120, pp. 175-185, 2014.

[89] S. Ritter and T. T. Dinh, "Capsaicin-induced neuronal degeneration in the brain and retina of preweanling rats," Journal of Comparative Neurology, vol. 296, no. 3, pp. 447-461, 1990.

[90] R. M. Sappington, T. Sidorova, D. J. Long, and D. J. Calkins, "TRPV1: contribution to retinal ganglion cell apoptosis and increased intracellular $\mathrm{Ca}^{2+}$ with exposure to hydrostatic pressure," Investigative Ophthalmology \& Visual Science, vol. 50, no. 2, pp. 717-728, 2009.

[91] K. Sakamoto, T. Kuroki, Y. Okuno et al., "Activation of the TRPV1 channel attenuates N-methyl-d-aspartic acid-induced neuronal injury in the rat retina," European Journal of Pharmacology, vol. 733, no. 1, pp. 13-22, 2014.

[92] A. R. Green, A. H. Hainsworth, and D. M. Jackson, "GABA potentiation: a logical pharmacological approach for the treatment of acute ischaemic stroke," Neuropharmacology, vol. 39, no. 9, pp. 1483-1494, 2000.
[93] J. Nguyen-Legros, C. Versaux-Botteri, and P. Vernier, "Dopamine receptor localization in the mammalian retina," Molecular Neurobiology, vol. 19, no. 3, pp. 181-204, 1999.

[94] P. Witkovsky, "Dopamine and retinal function," Documenta Ophthalmologica, vol. 108, no. 1, pp. 17-40, 2004.

[95] S. Sekaran, J. Cunningham, M. J. Neal, N. A. Hartell, and M. B. A. Djamgoz, "Nitric oxide release is induced by dopamine during illumination of the carp retina: serial neurochemical control of light adaptation," European Journal of Neuroscience, vol. 21, no. 8, pp. 2199-2208, 2005.

[96] O. Bugnon, N. C. Schaad, and M. Schorderet, "Nitric oxide modulates endogenous dopamine release in bovine retina," NeuroReport, vol. 5, no. 4, pp. 401-404, 1994.

[97] M. B. A. Djamgoz, J. R. Cunningham, S. L. Davenport, and M. J. Neal, "Nitric oxide inhibits depolarization-induced release of endogenous dopamine in the rabbit retina," Neuroscience Letters, vol. 198, no. 1, pp. 33-36, 1995.

[98] D. Yu and W. D. Eldred, "Nitric oxide stimulates $\gamma$-aminobutyric acid release and inhibits glycine release in retina," Journal of Comparative Neurology, vol. 483, no. 3, pp. 278-291, 2005.

[99] A. Vasilaki, M. Mouratidou, S. Schulz, and K. Thermos, "Somatostatin mediates nitric oxide production by activating sst $_{2}$ receptors in the rat retina," Neuropharmacology, vol. 43, no. 5, pp. 899-909, 2002.

[100] E. Kouvidi, Z. Papadopoulou-Daifoti, and K. Thermos, "Somatostatin modulates dopamine release in rat retina," Neuroscience Letters, vol. 391, no. 3, pp. 82-86, 2006.

[101] F. Kiagiadaki, E. Koulakis, and K. Thermos, "Dopamine (D1) receptor activation and nitrinergic agents influence somatostatin levels in rat retina," Experimental Eye Research, vol. 86, no. 1, pp. 18-24, 2008.

[102] B. Gonzalez, F. Paz, L. Florán, J. Aceves, D. Erlij, and B. Florán, "Cannabinoid agonists stimulate $[3 \mathrm{H}] \mathrm{GABA}$ release in the globus pallidus of the rat when $G_{i}$ protein-receptor coupling is restricted: role of dopamine D2 receptors," Journal of Pharmacology and Experimental Therapeutics, vol. 328, no. 3, pp. 822828, 2009. 

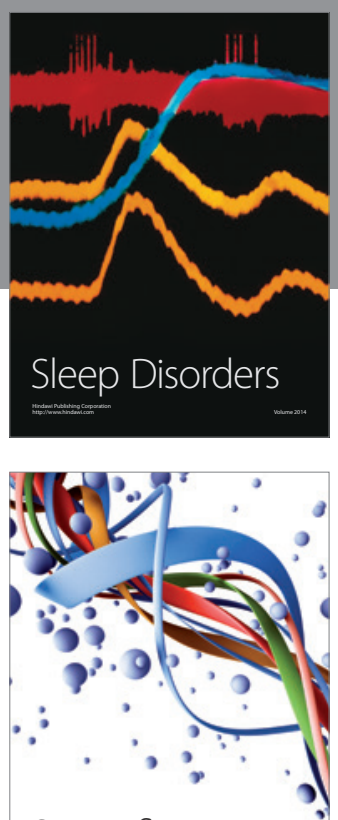

Scientifica
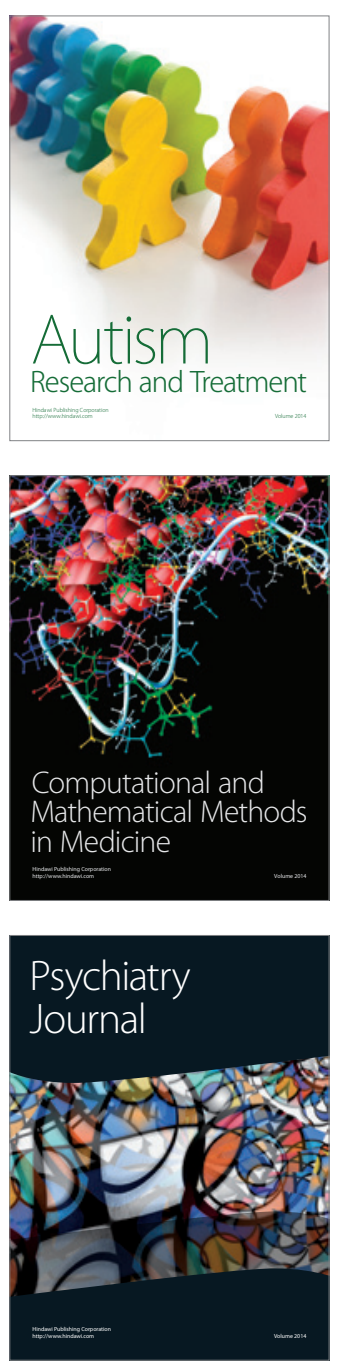
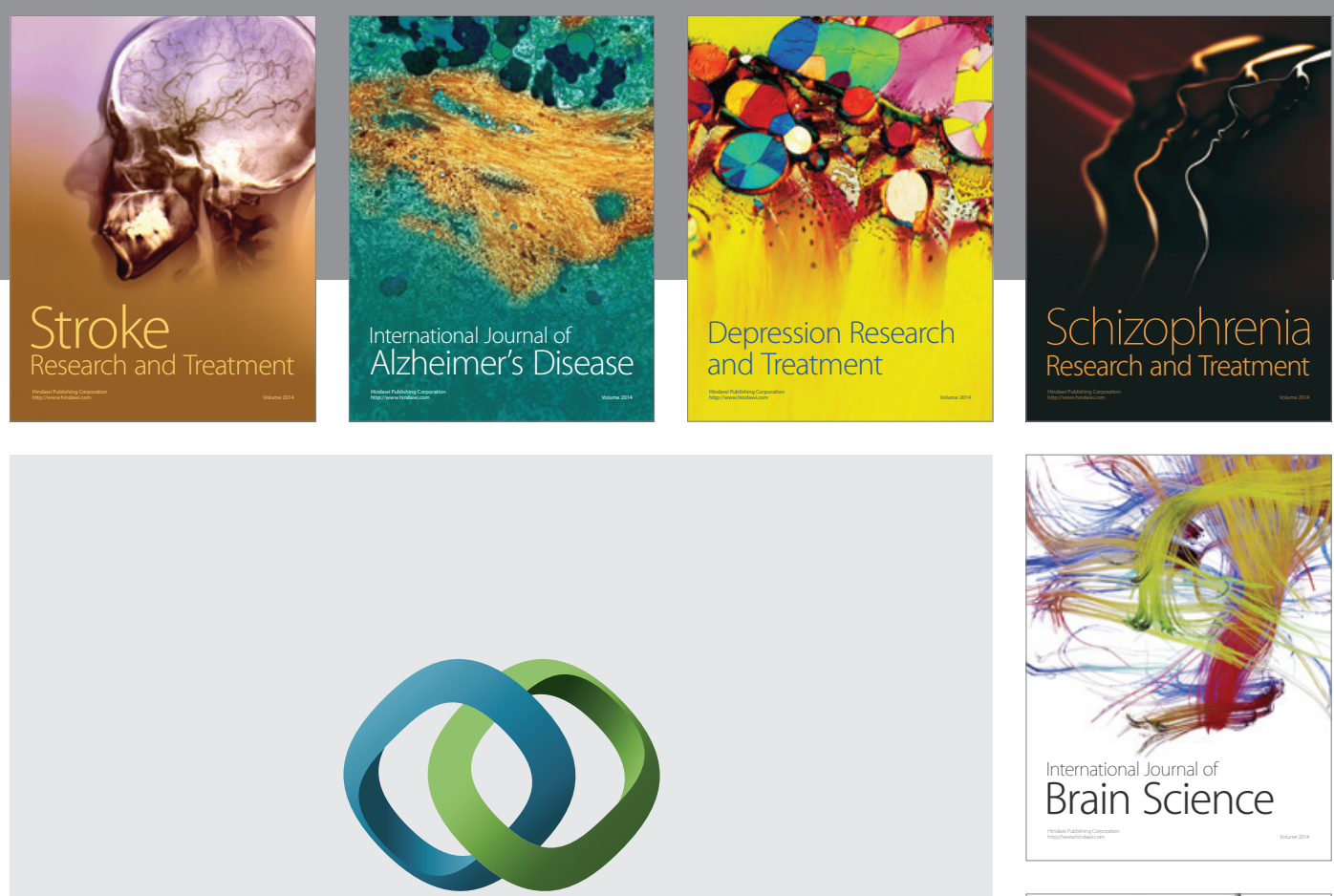

\section{Hindawi}

Submit your manuscripts at

http://www.hindawi.com
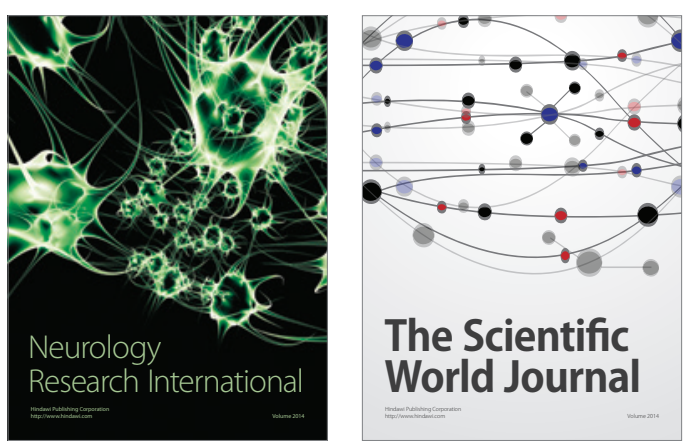

The Scientific World Journal

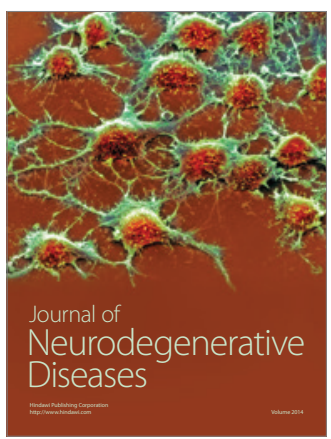

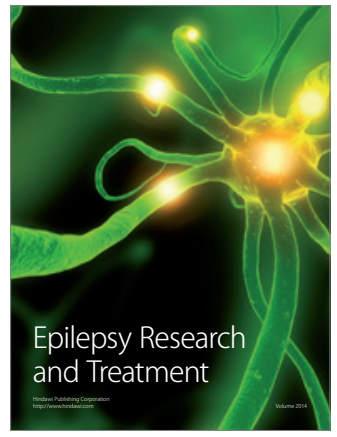

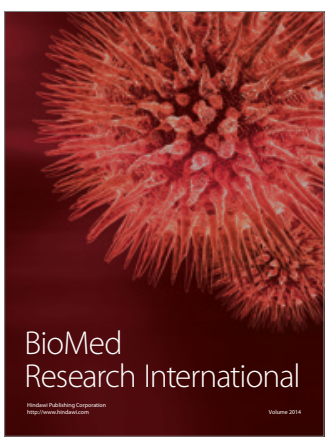

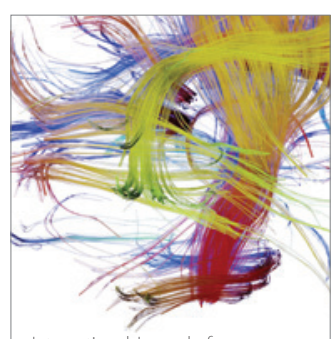

Brain Science

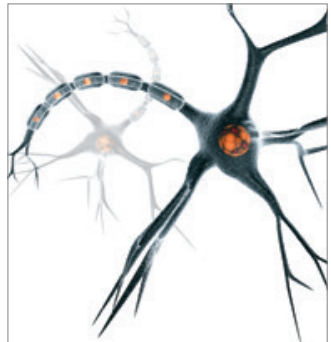

Neural Plasticity
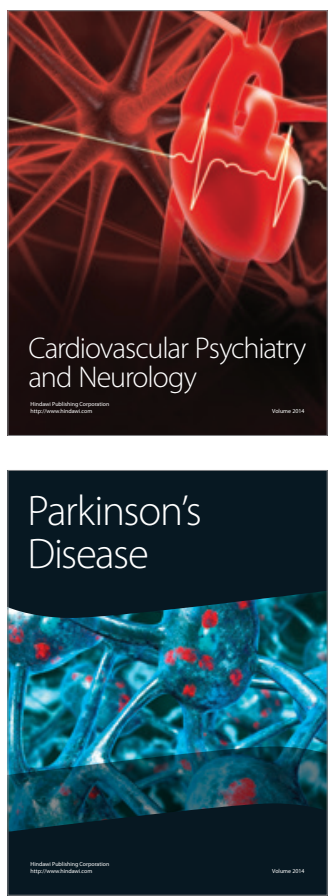